\title{
Biochar Modified by Nano-manganese Dioxide as Adsorbent and Oxidant for Oxytetracycline
}

\author{
Lirong Feng ${ }^{1,2} \cdot$ Guodong Yuan ${ }^{3}$ (1) $\cdot$ Liang Xiao ${ }^{1} \cdot$ Jing Wei ${ }^{1} \cdot$ Dongxue $\mathrm{Bi}^{1}$
}

Received: 7 December 2019 / Accepted: 17 February 2020

(C) Springer Science+Business Media, LLC, part of Springer Nature 2020

\begin{abstract}
Biochar has limited capacity to adsorb oxytetracycline (OTC). Here we have used bamboo willow biochar (BC) as a carrier to produce $\mathrm{nMnO}_{2}$-loaded biochars (MBC) by a co-precipitation method. Their chemical compositions, morphological features, specific surface area, and surface functional groups were observed or determined. Batch experiments were conducted to assess the effects of reaction time, initial OTC concentrations, $\mathrm{pH}$, salt concentrations, and natural organic matter (NOM) on OTC removal. Kinetics and isotherms indicated that OTC was mainly adsorbed via chemical interactions, and mono- and multi-layer adsorption occurred on the surface. MBC removed 19-25 times more OTC than BC, and the removal was highest at near-neutral $\mathrm{pH}$, not influenced by $\mathrm{NaCl}(2,10 \mathrm{mM})$, slighted reduced by $\mathrm{NOM}\left(0-20 \mathrm{mg} \mathrm{L}^{-1}\right)$, and enhanced by $\mathrm{NaHCO}_{3}$ $(2,10 \mathrm{mM})$. Besides being an adsorbent, MBC acted as an oxidant and degraded 58.5\% of OTC at $24 \mathrm{~h}$.
\end{abstract}

Keywords Biochar $\cdot$ Oxytetracycline $\cdot$ Nano-manganese dioxide $\cdot$ Adsorption $\cdot$ Degradation

Antibiotics in aquatic environments is a vital class of contaminants of emerging concern due to their extensive usage and environmental implications (Peiris et al. 2017). Being a member of tetracycline antibiotics (TCs) family, oxytetracycline (OTC) has been widely used in aquaculture and animal husbandry (Chen and Huang 2011; Jia et al. 2016). The high persistence and recalcitrance of OTC could induce antibiotic resistance genes and cause its bioaccumulation in the aquatic ecosystem (Jeong et al. 2010; Yuan et al. 2019). Thus, OTC immobilization in or removal from the aquatic environment is highly desirable.

Biochar (BC) as an adsorbent for antibiotics has been intensively investigated (Peiris et al. 2017). Its adsorption capacity for antibiotics, however, is generally low (Zhou et al. 2017). For example, BC produced from Robinia

Guodong Yuan

yuanguodong@zqu.edu.cn

1 Yantai Institute of Coastal Zone Research, Chinese Academy of Sciences, Yantai 264003, Shandong, China

2 University of Chinese Academy of Sciences, Beijing 100049, China

3 Guangdong Provincial Key Laboratory of Environmental Health and Land Resource, School of Environmental and Chemical Engineering, Zhaoqing University, Zhaoqing 526061, Guangdong, China pseudoacacia had an OTC adsorption of $10-15 \mathrm{mg} \mathrm{g}^{-1}$ (Xiao et al. 2019). Thus, modifications of $\mathrm{BC}$ have been proposed to enhance its performance. The synthesis of $\mathrm{BC}$ based nanocomposites, for example, has recently become a research hotspot (Gao et al. 2018; Liang et al. 2017; Narvaez et al. 2019). Nano- $\mathrm{MnO}_{2}\left(\mathrm{nMnO}_{2}\right)$-modified $\mathrm{BC}$ showed great potential for removing heavy metals and organic contaminants (Narvaez et al. 2019). For example, Gao et al. (2018) reported that $\mathrm{MnO}_{2}-\mathrm{BC}$ nanocomposites effectively removed di-n-butyl phthalate and OTC from aqueous solutions. Recently Jung et al. (2019) found the catalytic degradation of bisphenol $\mathrm{A}$ in water by $\mathrm{MnO}_{2}$-modified $\mathrm{BC}$. The large surface area and oxidative capacity of $\mathrm{nMnO}_{2}$ contributed to the enhanced adsorption and abiotic decomposition (Mahamallik et al. 2015; Song et al. 2019). Biochar averted the agglomeration of $\mathrm{nMnO}_{2}$, thus enabling the efficient use of $\mathrm{nMnO}_{2}$ (Jung et al. 2019).

Despite the above signs of progress, systematic studies are rare on how does the assembling of $\mathrm{nMnO}_{2}-\mathrm{BC}$ composites affect their adsorptive and oxidative ability for antibiotics under various environmental conditions. This study aimed to (1) synthesize $\mathrm{nMnO}_{2}-\mathrm{BC}$ nanocomposites with different $\mathrm{BC} / \mathrm{MnO}_{2}$ ratios; (2) assess their potential for OTC removal as influenced by $\mathrm{pH}$, salt compositions and contents, and organic carbon content; and (3) reveal the dual functions of MBC on adsorbing and degrading OTC. 


\section{Materials and Methods}

OTC ( $>98 \%$ purity) from Aladdin Reagent (Shanghai) Co, Ltd was used to prepare a stock solution of $500 \mathrm{mg}$ $\mathrm{L}^{-1}$ with methanol (HPLC-grade) and ultra-pure water and stored in a refrigerator at $4{ }^{\circ} \mathrm{C}$ in the dark for use within a week. Branches of bamboo willow (Salix fragilis L.) were collected from a farm in Dongying City of Shandong Province, China, as feedstock to produce biochar in the field via an aerobic carbonization process and a fire and water coupled method (Xiao et al. 2019). The retention time was $0 \mathrm{~min}$. The formed biochar was homogenized, ground, and passed through a 60-mesh sieve, then dried at $80^{\circ} \mathrm{C}$ and labeled as $\mathrm{BC} . \mathrm{nMnO}_{2}$ modified $\mathrm{BC}(\mathrm{MBC})$ was synthesized using the co-precipitation method (Liang et al. 2017; Mahamallik et al. 2015). Briefly, BC (5.22 g) was dispersed in $300 \mathrm{~mL}$ of $\mathrm{MnSO}_{4}$ solution $(6,12,24 \mathrm{mM}$ ) and ultra-sonicated for $1 \mathrm{~h}$. Then, $10 \mathrm{~mL} \mathrm{KMnO}_{4}$ solution $(4,8,16 \mathrm{mM})$ were dropwise added with continuous stirring. In the end, the suspension was stirred for a further $30 \mathrm{~min}$, then filtered, washed with ultra-pure water three times, and dried in a vacuum oven at $80^{\circ} \mathrm{C}$ for $12 \mathrm{~h}$ to obtain MBC samples with $\mathrm{BC} / \mathrm{MnO}_{2}$ ratios of 40:1, 20:1, and 10:1.

The ash content of $\mathrm{BC}$ and $\mathrm{MBC}$ was obtained by heating in a muffle furnace at $800^{\circ} \mathrm{C}$ for $4 \mathrm{~h}$. The $\mathrm{C}, \mathrm{H}$, and $\mathrm{N}$ contents of $\mathrm{BC}$ and $\mathrm{MBC}$ were analyzed using an elemental analyzer (Elementar Micro cube, Germany). The specific surface areas $\left(\mathrm{S}_{\mathrm{BET}}\right)$ of the samples were determined by $\mathrm{N}_{2}$ adsorption at $77 \mathrm{~K}$ using an Autosorb- 1 gas analyzer (Quantachrome Autosorb-iQ, USA), and applying the Brunauer-Emmett-Teller equation. A scanning electron microscope (SEM) (Hitachi S4800, Japan) was used to observe the surface morphology of the samples. A Fourier transform infrared (FTIR) spectrometer (Thermo Fisher Nicolet iS50, USA) was used to record the spectra of $\mathrm{BC}$ and $\mathrm{MBC}$ with a resolution of $2 \mathrm{~cm}^{-1}$ over the $400-4000 \mathrm{~cm}^{-1}$ wavenumber region. The zero point charge $\left(\mathrm{pH}_{\mathrm{pzc}}\right.$ ) of MBC was determined by salt titration (Jang et al. 2018).

Batch experiments were carried out in triplicate to investigate the effect of $\mathrm{pH}$, salt species and concentrations, and NOM on OTC sorption by $\mathrm{BC}$ and MBC. Briefly, BC and MBC (20 mg) were added to OTC solutions $(30 \mathrm{~mL})$ at $25^{\circ} \mathrm{C}$. Except for the isothermal experiment to study the effect of initial concentrations, OTC concentration was $100 \mathrm{mg} \mathrm{L}^{-1}$. The suspensions of $\mathrm{BC}-$ and MBC-OTC were shaken at $120 \mathrm{rpm}$ on an oscillator, sampled and filtered through a $0.45 \mu \mathrm{m}$ filter. The sampling times in the kinetic experiment were $0,5,15,30,60,120$, 240, 480, 720, 960, and $1440 \mathrm{~min}$. The initial concentrations of OTC in the isotherm experiment were 10, 20, 50,
$100,150,200,250,300 \mathrm{mg} \mathrm{L}^{-1}$. The solution $\mathrm{pH}$ was adjusted to 3-11 with $0.1 \mathrm{M} \mathrm{HCl}$ and $\mathrm{NaOH}$. Salts $(\mathrm{NaCl}$ and $\mathrm{NaHCO}_{3}$ ) at 2 and $10 \mathrm{mmol} \mathrm{L}^{-1}$, being the typical ion concentrations in freshwater and brackish aquaculture water, were used as background electrolytes. Humic acid from Yuanye Biotechnology Co, Ltd was used (0-20 mg $\mathrm{L}^{-1}$ ) as a NOM. Further, OTC adsorption on MBC was differentiated from OTC degradation by $\mathrm{nMnO}_{2}$ via the addition of $4 \mathrm{mg} \mathrm{mL}^{-1}$ oxalic acid to the suspensions to dissolve $\mathrm{nMnO}_{2}$ in $\mathrm{MBC}$ and thus immediately quench OTC oxidation by $\mathrm{nMnO}_{2}$ (Rubert and Pedersen 2006).

Sorption kinetics were evaluated by the pseudo-firstorder (PFO), pseudo-second-order (PSO), and Elovich models, as follows:

$Q_{t}=Q_{e}\left(1-\exp \left(-k_{1} t\right)\right)$

$Q_{t}=k_{2} Q_{e}^{2} t /\left(1+k_{2} Q_{e} t\right)$

$Q_{t}=(\ln (a b)) / b+(\ln t) / b$

where $Q_{\mathrm{e}}\left(\mathrm{mg} \mathrm{g}^{-1}\right)$ and $Q_{t}\left(\mathrm{mg} \mathrm{g}^{-1}\right)$ represent the OTC adsorption capacity at equilibrium time and time $\mathrm{t}(\mathrm{min})$, respectively; $k_{1}\left(\mathrm{~min}^{-1}\right)$ and $k_{2}\left(\mathrm{mg} \mathrm{g}^{-1} \mathrm{~min}^{-1 / 2}\right)$ are the rate constant of the PFO and PSO, respectively; $a$ is the chemical adsorption rate constant; $b$ is the surface covering constant.

The Langmuir and Freundlich models were used to fit isotherm adsorption data, and the equations are:

$Q_{e}=Q_{m} K_{L} C_{e} /\left(1+K_{L} C_{e}\right)$

$Q_{e}=K_{F} C_{e}^{1 / n}$

where $Q_{e}\left(\mathrm{mg} \mathrm{g}^{-1}\right)$ is the amount of OTC adsorbed at equilibrium, $Q_{\mathrm{m}}\left(\mathrm{mg} \mathrm{g}^{-1}\right)$ is the maximum adsorption capacity under monolayer coverage; $C_{\mathrm{e}}\left(\mathrm{mg} \mathrm{L}^{-1}\right)$ is OTC concentration at equilibrium; $K_{\mathrm{L}}\left(\mathrm{L} \mathrm{mg}^{-1}\right)$ and $K_{\mathrm{F}}\left(\mathrm{mg}^{1-\mathrm{n}} \mathrm{L}^{\mathrm{n}} \mathrm{g}^{-1}\right)$ are the Langmuir and Freundlich constants, respectively; $1 / \mathrm{n}$ is the adsorption intensity.

OTC concentration was analyzed by HPLC (Agilent 1260 Infinity II) with a reversed-phase C-18 column $(100 \mathrm{~mm} \times 4.6 \mathrm{~mm}, 4 \mu \mathrm{m})$ and a diode array detector (DAD) at $355 \mathrm{~nm}$. The instrument parameters were as follows: $0.01 \mathrm{M}$ oxalic acid (85\%) and acetonitrile (15\%) (v:v) as the mobile phase; the flow rate at $1 \mathrm{~mL} \mathrm{~min}^{-1}$; the injection amount of $20 \mu \mathrm{L}$; and column temperature at $30^{\circ} \mathrm{C}$. Two standard samples were used for quality assurance/control in OTC analysis. The difference between the concentrations of OTC initially added and those remaining in solution at the end of the reaction, both analysed by HPLC, were used to calculate the amount of OTC removed by BC and MBC. Inductively coupled plasma mass spectrometry (ICP-MS, 
Agilent 7800) was used to determine the concentration of dissolved Mn from the sorption experiment.

\section{Results and Discussion}

As Mn-loading increased, $\mathrm{C}$ and $\mathrm{N}$ contents of MBC decreased (Table 1), whereas ash content rose. Meanwhile, the increase in $\mathrm{H} / \mathrm{C}$ and $\mathrm{O} / \mathrm{C}$ indicated that $\mathrm{MnO}_{2}$ loading weakened $\mathrm{BC}$ aromaticity. The near-spherical particles on the surface of MBC (20:1) (Fig. 1a) and energy-dispersive $\mathrm{X}$-ray spectroscopic (EDS) patterns (Fig. 1b) confirmed the existence of $\mathrm{nMnO}_{2}$. Figure $2 \mathrm{a}$ shows the main functional groups of $\mathrm{BC}$ and $\mathrm{MBC}$, including $-\mathrm{OH}\left(3424 \mathrm{~cm}^{-1}\right)$, $\mathrm{C}=\mathrm{O} / \mathrm{C}=\mathrm{C}\left(1561-1577 \mathrm{~cm}^{-1}, 1421-1437 \mathrm{~cm}^{-1}\right), \mathrm{C}-\mathrm{O}$ $\left(1039 \mathrm{~cm}^{-1}\right)$ and aromatic $\mathrm{C}-\mathrm{H}\left(875 \mathrm{~cm}^{-1}\right)$ (Liang et al. 2017; Wei et al. 2019; Wu et al. 2019). After $\mathrm{nMnO}_{2}$ loading, the absorption band of $\mathrm{C}=\mathrm{O} / \mathrm{C}=\mathrm{C}$ and $\mathrm{C}-\mathrm{H}$ weakened sequentially, further proving the weakening of $\mathrm{BC}$ aromaticity. Meanwhile, $\mathrm{Mn}-\mathrm{O}$ peaks at $518 \mathrm{~cm}^{-1}$ gradually enhanced. As Liang et al. (2017) and Gao et al. (2018) reported, these simultaneous changes suggest that the aromatic ring of $\mathrm{BC}$ is the site to bind $\mathrm{MnO}_{2}$.
Figure 3 shows that $\mathrm{nMnO}_{2}$ loading on biochar greatly enhanced its removal capacity for OTC. As expected, the removal capacity further increased with the reaction time and OTC concentration. Calculated from the PSO equation, the equilibrium adsorption capacities at the initial OTC concentration of $100 \mathrm{mg} \mathrm{L}^{-1}$ were $8.31 \mathrm{mg} \mathrm{g}^{-1}$ for $\mathrm{BC}$, $114.13 \mathrm{mg} \mathrm{g}^{-1}$ for MBC (40:1), $128.56 \mathrm{mg} \mathrm{g}^{-1}$ for MBC (20:1), and $144.09 \mathrm{mg} \mathrm{g}^{-1}$ for MBC (10:1). The parameters in Table 2 show that the Elovich model fitted on adsorption data best $\left(R^{2}>0.95\right)$, suggesting that OTC was mainly adsorbed onto BC and MBC via chemical action (Yuan et al. 2019).

The fitting results of isotherm adsorption (Table 3) showed that OTC removal by BC was more in line with the Freundlich model, indicating heterogeneous multilayer adsorption. It is similar to the reports of Yuan et al. (2019) and Zhou et al. (2017). Both the Langmuir and Freundlich models fit OTC removal on MBC, which suggested that both monolayer and multilayer adsorption would occur at the surface (Jang et al. 2018). The maximum adsorption capacity of MBC for OTC, obtained from the Langmuir model, reached 292.53 (MBC40:1), 360.50 (MBC20:1), and $383.39 \mathrm{mg} \mathrm{g}^{-1}$ (MBC10:1), which were about 19, 24, and 25 times higher than that of $\mathrm{BC}\left(14.56 \mathrm{mg} \mathrm{g}^{-1}\right)$, respectively.
Table 1 The specific surface area, ash content, and element compositions of biochars

\begin{tabular}{llllllllll}
\hline Samples & $\begin{array}{l}\text { Specific } \\
\text { surface area } \\
\left(\mathrm{m}^{2} \mathrm{~g}^{-1}\right)\end{array}$ & Ash $(\%)$ & \multicolumn{6}{l}{ Elemental compositions on ash-free base $(\%)$} & \\
\cline { 5 - 10 } & & & $\mathrm{C}$ & $\mathrm{H}$ & $\mathrm{N}$ & $\mathrm{O}$ & $\mathrm{H} / \mathrm{C}$ & $\mathrm{O} / \mathrm{C}$ \\
\hline BC & 262.2 & $20.08 \pm 0.39$ & $82.21 \pm 0.01$ & $2.34 \pm 0.01$ & $0.65 \pm 0.01$ & 14.80 & 0.028 & 0.180 \\
MBC (40:1) & 285.9 & $22.03 \pm 0.54$ & $80.90 \pm 0.90$ & $2.83 \pm 0.13$ & $0.58 \pm 0.03$ & 15.69 & 0.035 & 0.194 \\
MBC (20:1) & 299.5 & $22.46 \pm 0.19$ & $80.39 \pm 0.00$ & $2.74 \pm 0.02$ & $0.55 \pm 0.01$ & 16.32 & 0.034 & 0.203 \\
MBC (10:1) & 278.6 & $23.82 \pm 0.39$ & $79.43 \pm 0.17$ & $2.88 \pm 0.03$ & $0.54 \pm 0.01$ & 17.14 & 0.036 & 0.216 \\
\hline
\end{tabular}
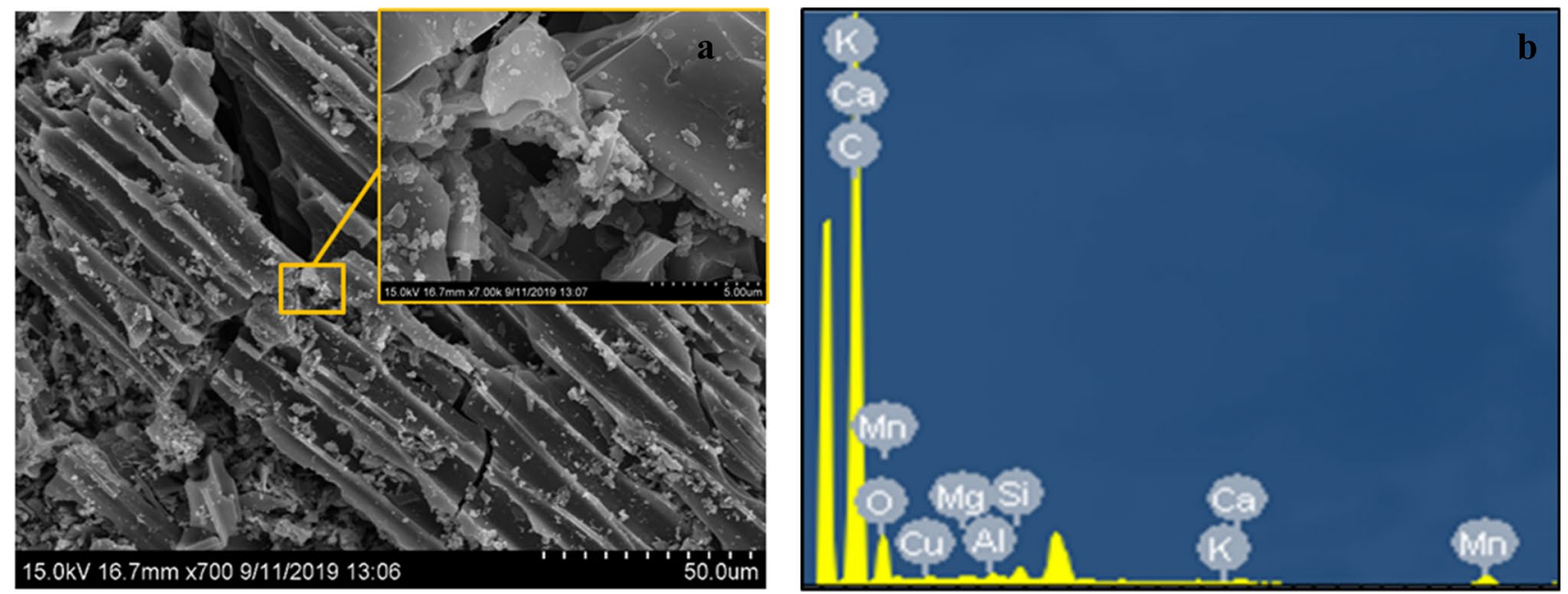

Fig. 1 SEM images and EDS patterns of MBC (20:1) 

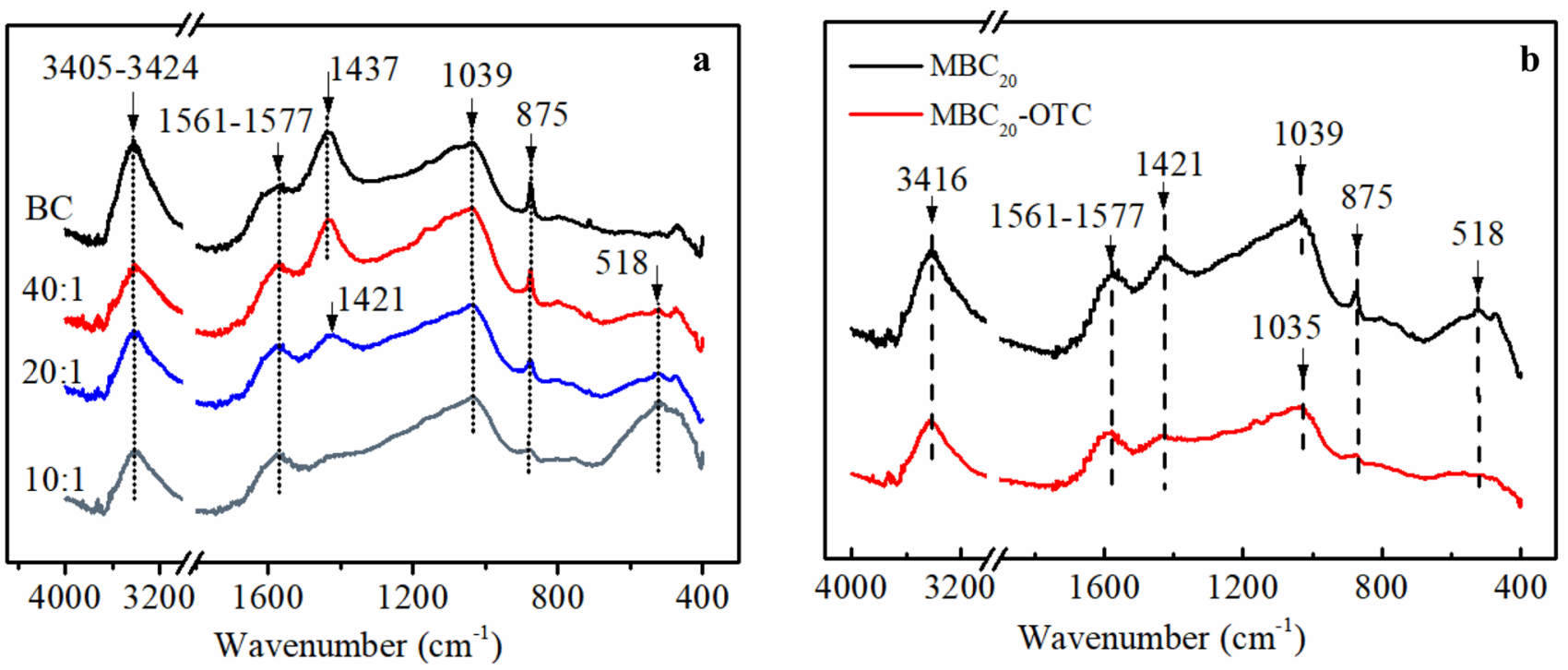

Fig. 2 FTIR spectra of $\mathrm{BC} / \mathrm{MBC}(40-10: 1)$ and $\mathrm{MBC}_{20}$ before and after OTC adsorption
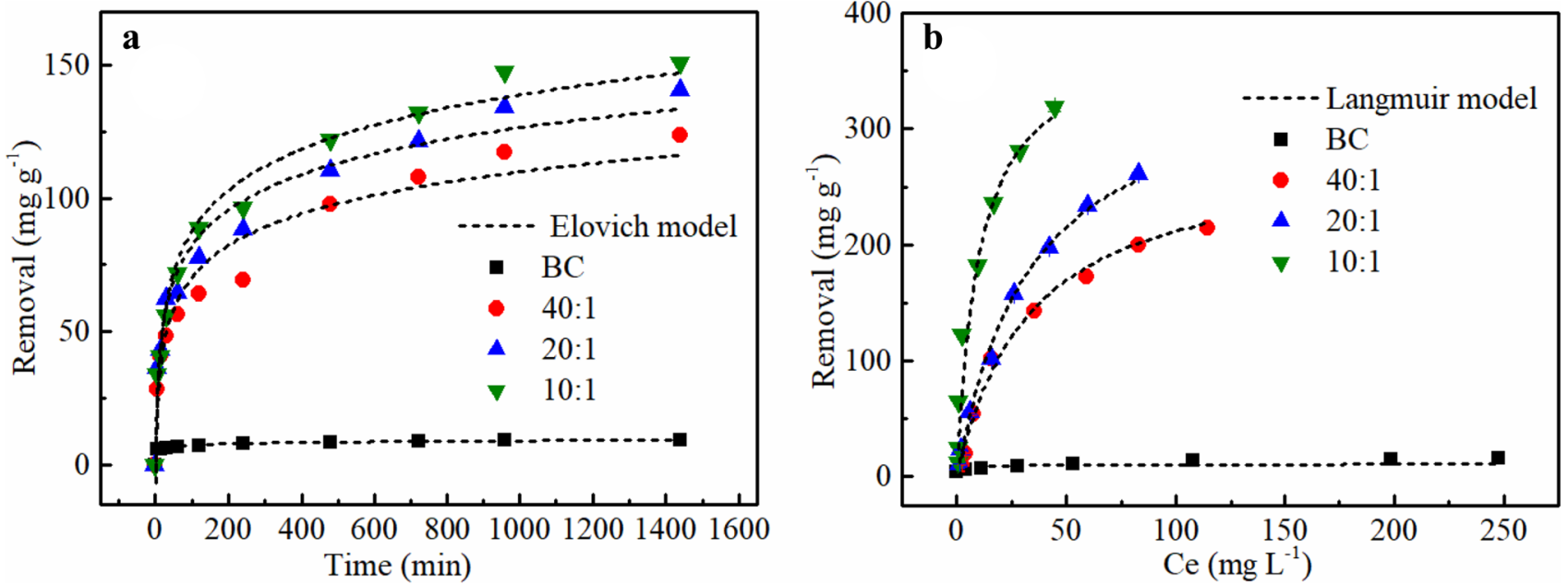

Fig. 3 Effect of reaction time (a) and OTC concentrations (b) on OTC adsorption on BC and MBC (40-10:1)

Table 2 Kinetics fitting parameters for OTC adsorption onto $\mathrm{BC}$ and $\mathrm{MBC}$

\begin{tabular}{|c|c|c|c|c|c|c|c|c|c|}
\hline \multirow[t]{2}{*}{ Samples } & \multicolumn{3}{|c|}{ Pseudo-first order model } & \multicolumn{3}{|c|}{ Pseudo-second order model } & \multicolumn{3}{|c|}{ Elovich model } \\
\hline & $\begin{array}{l}Q_{\mathrm{e}} \\
\left(\mathrm{mg} \mathrm{g}^{-1}\right)\end{array}$ & $\begin{array}{l}k_{1} \\
\left(\min ^{-1}\right)\end{array}$ & $R^{2}$ & $\begin{array}{l}Q_{\mathrm{e}} \\
\left(\mathrm{mg} \mathrm{g}^{-1}\right)\end{array}$ & $\begin{array}{l}k_{2} \\
\left(\mathrm{~g} \mathrm{mg}^{-1} \mathrm{~min}^{-1}\right)\end{array}$ & $R^{2}$ & $a$ & $b$ & $R^{2}$ \\
\hline $\mathrm{BC}$ & 7.86 & 0.209 & 0.799 & 8.31 & 0.0293 & 0.886 & 233.40 & 1.414 & 0.991 \\
\hline $\operatorname{MBC}(40: 1)$ & 105.15 & 0.012 & 0.782 & 114.13 & 0.0002 & 0.874 & 10.24 & 0.058 & 0.956 \\
\hline $\operatorname{MBC}(20: 1)$ & 118.43 & 0.015 & 0.800 & 128.56 & 0.0002 & 0.889 & 15.17 & 0.056 & 0.970 \\
\hline $\operatorname{MBC}(10: 1)$ & 131.43 & 0.013 & 0.869 & 144.09 & 0.0001 & 0.935 & 11.31 & 0.045 & 0.979 \\
\hline
\end{tabular}

Environmental conditions in water bodies would affect OTC removal by $\mathrm{BC}$ and $\mathrm{MBC}$. Based on the tradeoff of preparation cost and adsorptive performance of $\mathrm{MBC}, \mathrm{MBC}_{20}$ was chosen as the scavenger to assess the effects of $\mathrm{pH}$, salts, and NOM on OTC removal from water. 
Table 3 Isothermal fitting parameters of OTC adsorption onto $\mathrm{BC}$ and $\mathrm{MBC}$

\begin{tabular}{lcllllll}
\hline Samples & \multicolumn{2}{l}{ Langmuir } & & & Freundlich \\
\cline { 2 - 3 } & $Q_{m}\left(\mathrm{mg} \mathrm{g}^{-1}\right)$ & $K_{\mathrm{L}}\left(\mathrm{L} \mathrm{mg}^{-1}\right)$ & $R^{2}$ & & $K_{\mathrm{F}}\left(\mathrm{mg}^{1-\mathrm{n}} \mathrm{L}^{\mathrm{n}} \mathrm{g}^{-1}\right)$ & $1 / n$ & $R^{2}$ \\
\hline BC & 14.56 & 0.1077 & 0.779 & 4.3985 & 0.2376 & 0.977 \\
MBC (40:1) & 292.53 & 0.0299 & 0.974 & 28.7714 & 0.4397 & 0.973 \\
MBC (20:1) & 360.50 & 0.0296 & 0.995 & 28.9789 & 0.5053 & 0.982 \\
MBC (10:1) & 383.39 & 0.0973 & 0.937 & 73.2574 & 0.3967 & 0.965 \\
\hline
\end{tabular}

$\mathrm{pH}$ can affect OTC adsorption by changing the surface charge of biochar and the ionization degree of OTC (Jia et al. 2016; Aghababaei et al. 2017). With ionization constants of $\mathrm{pK}_{\mathrm{a} 1}=3.22, \mathrm{pK}_{\mathrm{a} 2}=7.46$, and $\mathrm{pK}_{\mathrm{a} 3}=8.94$, OTC can exist as cation $\left(\mathrm{OTC}^{+}\right)$, zwitterion $\left(\mathrm{OTC}^{0}\right)$, or anion $\left(\mathrm{OTC}^{-}\right.$or $\mathrm{OTC}^{2-}$ ), depending on ambient $\mathrm{pH}$. The maximum removal of OTC by $\mathrm{MBC}_{20}$ occurred at $\mathrm{pH} 5$ (Fig. 4a), indicating that the $\pi-\pi$ electron-donor-acceptor (EDA) interaction between neutral OTC molecule and $\mathrm{MBC}_{20}$ played an important role in adsorption. In other words, OTC acted as an electron
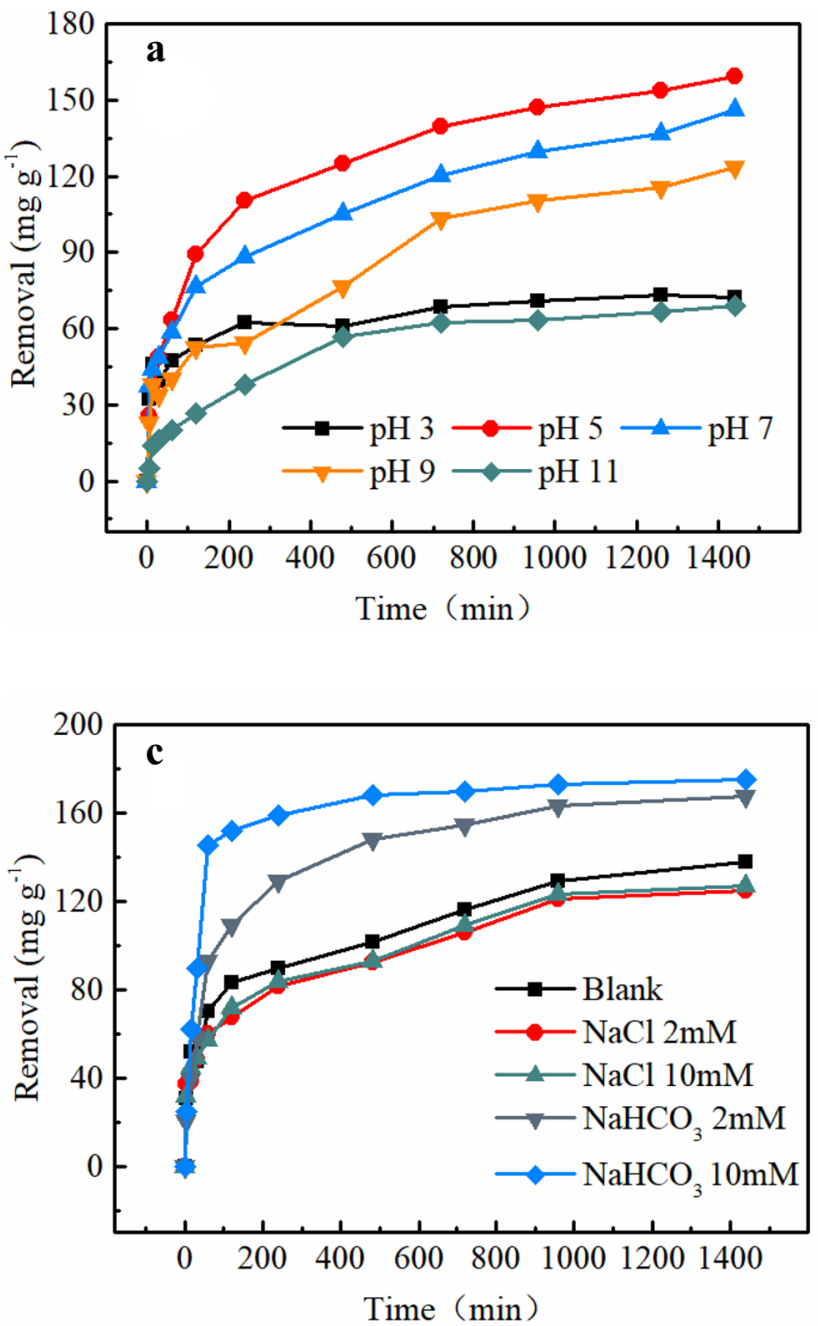

acceptor due to the strong electron-withdrawing ability of its ketone group, whereas the aromatic rings of $\mathrm{BC}$ made it an electron donor. As $\mathrm{pH}$ was lowered to 3 or raised to 11 , the removal capacity decreased. This decrease was due to the electrostatic repulsion between $\mathrm{MBC}_{20}$ and OTC under strong acidic and alkaline conditions (Yuan et al. 2019). With a $\mathrm{pH}_{\mathrm{pzc}}$ of $9.18, \mathrm{MBC}_{20}$ was positively charged on the acidic side of $\mathrm{pH}_{\mathrm{pzc}}$ and negatively charged at $\mathrm{pH}>9.18$.

Being a common organic component in water, humic acid (HA) had a competitive effect on OTC adsorption onto
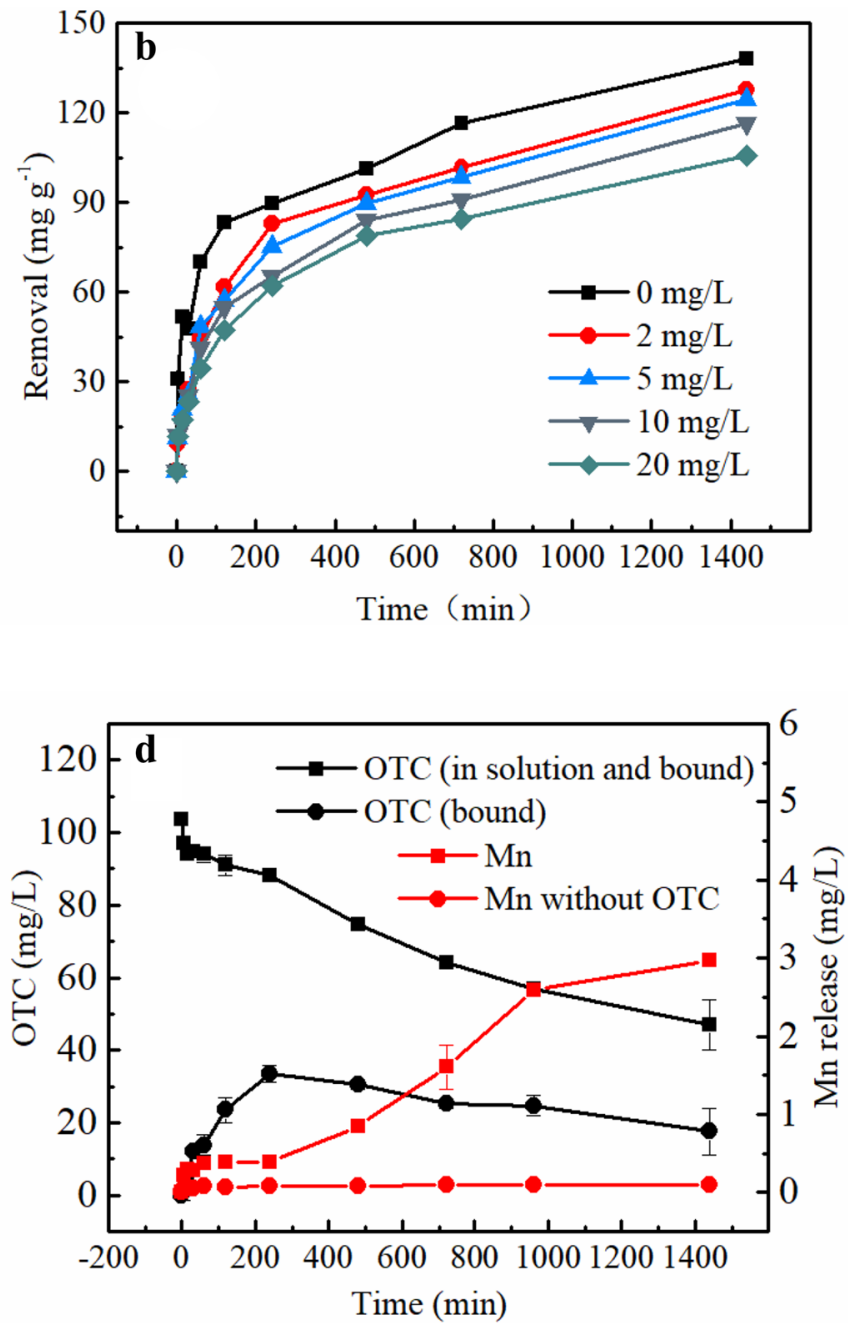

Fig. 4 Effect of $\mathrm{pH}(\mathbf{a}), \mathrm{NOM}(\mathbf{b})$, and salts (c) on OTC removal by $\mathrm{MBC}_{20}$, and $\mathrm{Mn}^{2+}$ release (d) at different times of reaction 
$\mathrm{MBC}_{20}$ (Fig. 4b). HA can complex with cationic or zwitterionic OTC species through electrostatic attraction (mainly carboxylic groups) to hinder its mobility (Zhao et al. 2012), and may also compete with OTC for active sites on $\mathrm{MBC}_{20}$ via van der Waals forces or $\pi-\pi$ EDA interaction (Xie et al. 2014).

Figure $4 \mathrm{c}$ showed the effect of salt species and concentrations on OTC removal. $\mathrm{NaCl}$ had little inhibition on OTC removal by $\mathrm{MBC}_{20}$, indicating that $\mathrm{Na}^{+}$and $\mathrm{Cl}^{-}$had no electrostatic screening effect on OTC adsorption, and $\mathrm{Na}^{+}$did not compete with OTC at the adsorptive sites of $\mathrm{MBC}_{20}$ (Song et al. 2019). In contrast, $\mathrm{NaHCO}_{3}$ enhanced OTC removal, which was concentration-dependent. $\mathrm{HCO}_{3}{ }^{-}$was able to precipitate the $\mathrm{Mn}^{2+}$ released from MBC (discussed below), thereby reducing interference of $\mathrm{Mn}^{2+}$ and increasing OTC removal.

Figure 4d demonstrated that OTC removal by MBC was accompanied by $\mathrm{Mn}^{2+}$ release, suggesting that $\mathrm{nMnO}_{2}$ acted as an oxidant during OTC removal (Gao et al. 2012; Mahamallik et al. 2015). After $24 \mathrm{~h}$ reaction at $\mathrm{pH} 5.0, \mathrm{Mn}^{2+}$ release reached $2.97 \mathrm{mg} \mathrm{L}^{-1}$ (about $8.91 \%$ of the theoretical value of loaded $\mathrm{MnO}_{2}$ ), much higher than the $0.10 \mathrm{mg}$ $\mathrm{L}^{-1}$ in control (Mn release without OTC). Meanwhile, OTC degradation by $\mathrm{nMnO}_{2}$ at $24 \mathrm{~h}$, estimated from the changes in OTC total (i.e. OTC in solution and OTC bound to $\mathrm{MBC}$ ), was $58.5 \%$. At $4 \mathrm{~h}$, the amount of OTC bound to $\mathrm{MBC}_{20}$ reached the maximum, approximately $38.0 \%$ of the total. Similarly, Song et al. (2019) reported that $\mathrm{Mn}^{2+}$ competed with tetracycline (TC) for adsorption and hindered the migration of electrons to TC, thus reducing TC adsorption on $\mathrm{MnO}_{2}$ surface. After $4 \mathrm{~h} \mathrm{Mn}{ }^{2+}$ release quickly increased, suggesting that the Mn originally complexed with OTC and bound to $\mathrm{MBC}_{20}$ was gradually released with the degradation of OTC (Rubert and Pedersen 2006). According to Chen and Huang (2011), during its oxidative degradation by $\mathrm{MnO}_{2}$, OTC did not undergo isomerization. Instead, $\mathrm{N}$-demethyl products with higher polarity were produced. Besides, N-demethyl derivatives, formaldehyde and hydroquinone products would also form. Importantly, the derivatives from OTC degradation have lower toxicity and pose less threat to the environment (Chen and Huang 2011).

The FTIR spectra (Fig. 2b) provided further evidence of the mechanisms of OTC removal by $\mathrm{MBC}_{20}$. The reduced intensity of the $\mathrm{C}=\mathrm{O} / \mathrm{C}=\mathrm{C}$ peak at $1421 \mathrm{~cm}^{-1}$ confirmed the presence of $\pi-\pi$ EDA interaction between MBC and OTC (Aghababaei et al. 2017; Yuan et al. 2019). Furthermore, the decrease in the $\mathrm{Mn}-\mathrm{O}$ bond at $518 \mathrm{~cm}^{-1}$ demonstrated that during OTC adsorption, $\mathrm{nMnO}_{2}$ was partly reduced to $\mathrm{Mn}^{2+}$ for release into the solution (Fig. 4d).

Though it was not intended to recover and reuse MBC because of its low value, $\mathrm{MBC}_{20}$ still showed reusability. Its OTC removal capacity was $140,106,70,53$, and $37 \mathrm{mg} \mathrm{g}^{-1}$ at the $1 \mathrm{st}, 2 \mathrm{nd}, 3 \mathrm{rd}, 4 \mathrm{th}$, and 5 th use, respectively.
In summary, biochar produced from Salix fragilis L. and further loaded with $\mathrm{nMnO}_{2}$ (MBC) was an inexpensive and high efficient scavenger to remove OTC from water. More OTC was removed at near-neutral $\mathrm{pH}$ than at either acidic or alkaline conditions. $\mathrm{NaCl}$ as an electrolyte apparently had little effect on OTC removal, but $\mathrm{NaHCO}_{3}$ enhanced the removal. DOM slightly reduced OTC removal by MBC. FTIR spectra suggested that $\pi-\pi$ EDA interaction was involved in OTC removal by MBC; the release of $\mathrm{Mn}^{2+}$ from $\mathrm{MBC}$ indicated that $\mathrm{nMnO}_{2}$ acted as an oxidant for the degradation of OTC, thus contributing to OTC removal. In other words, OTC removal was the combined result of its adsorption onto $\mathrm{MBC}$ and its degradation by $\mathrm{nMnO}_{2}$.

Acknowledgement This research was supported by Chinese National Key Research and Development Program (2016YFD0200303) and National Natural Science Foundation of China (41977139).

\section{Compliance with Ethical Standards}

Conflict of interest The authors declare that they have no conflict of interest.

\section{References}

Aghababaei A, Ncibi MC, Sillanpää M (2017) Optimized removal of oxytetracycline and cadmium from contaminated waters using chemically-activated and pyrolyzed biochars from forest and wood-processing residues. Bioresour Technol 239:28-36

Chen WR, Huang CH (2011) Transformation kinetics and pathways of tetracycline antibiotics with manganese oxide. Environ Pollut 159(5):1092-1100

Gao J, Hedman C, Liu C et al (2012) Transformation of sulfamethazine by manganese oxide in aqueous solution. Environ Sci Technol 46:2642-2651

Gao ML, Zhang Y, Gong XL et al (2018) Removal mechanism of di-n-butyl phthalate and oxytetracycline from aqueous solutions by nano-manganese dioxide modified biochar. Environ Sci Pollut Res 25:7796-7907

Jang HM, Yoo S, Choi YK et al (2018) Adsorption isotherm, kinetic modeling and mechanism of tetracycline on Pinus taeda-derived activated biochar. Bioresour Technol 259:24-31

Jeong J, Song WH, Cooper WJ et al (2010) Degradation of tetracycline antibiotics: mechanisms and kinetic studies for advanced oxidation/reduction processes. Chemosphere 78(5):533-540

Jia MY, Wang F, Jin X et al (2016) Metal ion-oxytetracycline interactions on maize straw biochar pyrolyzed at different temperatures. Chem Eng J 304:934-940

Jung KW, Lee SY, Lee YJ et al (2019) Ultrasound-assisted heterogeneous Fenton-like process for bisphenol a removal at neutral $\mathrm{pH}$ using hierarchically structured manganese dioxide/biochar nanocomposites as catalysts. Ultrason Sonochem 57:22-28

Liang J, Li XM, Yu ZG et al (2017) Amorphous $\mathrm{MnO}_{2}$ modified biochar derived from aerobically composted swine manure for adsorption of $\mathrm{Pb}(\mathrm{II})$ and $\mathrm{Cd}(\mathrm{II})$. ACS Sustain Chem Eng 5:5049-5058 
Mahamallik P, Saha S, Pal A (2015) Tetracycline degradation in aquatic environment by highly porous $\mathrm{MnO}_{2}$ nanosheet assembly. Chem Eng J 276:155-165

Narvaez OMR, Hernandez JMP, Goonetilleke A et al (2019) Biocharsupported nanomaterials for environmental applications. J Ind Eng Chem 78:21-33

Peiris C, Gunatilake SR, Mlsna TE et al (2017) Biochar based removal of antibiotic sulfonamides and tetracyclines in aquatic environments: a critical review. Bioresour Technol 246:150-159

Rubert KF, Pedersen JA (2006) Kinetics of oxytetracycline reaction with a hydrous manganese oxide. Environ Sci Technol 40:7216-7221

Song Z, Ma YL, Li CE (2019) The residual tetracycline in pharmaceutical wastewater was effectively removed by using $\mathrm{MnO}_{2}$ /graphene nanocomposite. Sci Total Environ 651:580-590

Wei J, Tu C, Yuan GD et al (2019) Assessing the effect of pyrolysis temperature on the molecular properties and copper sorption capacity of a halophyte biochar. Environ Pollut 251:56-65

Wu J, Lu J, Zhang C, Zhang ZH et al (2019) Adsorptive removal of tetracyclines and fluoroquinolones using Yak dung biochar. B Environ Contam Tox 102:407-412

Xiao L, Feng LR, Yuan GD et al (2019) Low-cost field production of biochars and their properties. Environ Geochem Health. https:// doi.org/10.1007/s10653-019-00458-5
Xie MX, Chen W, Xu ZY et al (2014) Adsorption of sulfonamides to demineralized pine wood biochars prepared under different thermochemical conditions. Environ Pollut 186:187-194

Yuan L, Yan M, Huang ZZ et al (2019) Influences of pH and metal ions on the interactions of oxytetracycline onto nano-hydroxyapatite and their co-adsorption behavior in aqueous solution. J Colloid Interface Sci 541:101-131

Zhao YP, Gu XY, Gao SX et al (2012) Adsorption of tetracycline (TC) onto montmorillonite: cations and humic acid effects. Geoderma 183-184:12-18

Zhou YY, Liu XC, Xiang YJ et al (2017) Modification of biochar derived from sawdust and its application in removal of tetracycline and copper from aqueous solution: adsorption mechanism and modelling. Bioresour Technol 245:266-273

Publisher's Note Publisher's Note Springer Nature remains neutral with regard to jurisdictional claims in published maps and institutional affiliations 